\title{
Intercalation of Ciprofloxacin in Naturally Occurring Smectite from Bana: Potentiality as Drug Delivery System and Antimicrobial Effects on Escherichia coli and Staphylococcus aureus
}

\author{
Carine Feudjio Memenfo1,2*, Nicolas Tabary², Jean Aimé Mbey¹, Stéphanie Degoutin², \\ Frédéric Cazaux², Maryse Bacquet², Mickaël Maton3', Bernard Martel2, Daniel Njopwouo' \\ ${ }^{1}$ Laboratory of Applied Inorganic Chemistry, Faculty of Science, University of Yaounde 1, Yaounde, Cameroon \\ ${ }^{2}$ Unité Matériaux et Transformations (UMET), UMR 8207, CNRS, INRA, ENSCL, University of Lille, Lille, France \\ ${ }^{3}$ INSERM, CHU Lille, U1008-Controlled Drug Delivery Systems and Biomaterials, University of Lille, Lille, France \\ Email: *memenfofeudjio@yahoo.fr
}

How to cite this paper: Memenfo, C.F., Tabary, N., Mbey, J.A., Degoutin, S., Cazaux, F., Bacquet, M., Maton, M., Martel, B. and Njopwouo, D. (2021) Intercalation of Ciprofloxacin in Naturally Occurring Smectite from Bana: Potentiality as Drug Delivery System and Antimicrobial Effects on Escherichia coli and Staphylococcus aureus. Journal of Materials Science and Chemical Engineering, 9, 21-40.

https://doi.org/10.4236/msce.2021.98003

Received: June 25, 2021

Accepted: August 23, 2021

Published: August 26, 2021

Copyright ( 2021 by author(s) and Scientific Research Publishing Inc. This work is licensed under the Creative Commons Attribution International License (CC BY 4.0).

http://creativecommons.org/licenses/by/4.0/

\begin{abstract}
Ciprofloxacin (CFX) was loaded on Bana clay (Cameroon) and CFX loadedclays have been evaluated as drug delivery system. Raw clays and CFX loaded compounds have been characterized by some physico-chemicals methods. In vitro release studies have been done in gastric and phosphate buffer experimental mediums; bacteriological studies have been made up on Escherichia coli and Staphylococcus aureus. X-ray diffractometry patterns of loaded compounds show a basal spacing increasing due to CFX intercalation. On Fourier-Transformed Infrared spectrometry spectra, appearance of CFX characteristic bands and shifting of certain bands already presents on clay confirmed CFX intercalation. After $96 \mathrm{~h}$ of CFX released from release mediums, prolonged and continue profiles have been observed. Diffusion tests displayed an inhibition radius of $\sim 2 \mathrm{~cm}$ on gelose seeded with Escherichia coli and Staphylococcus aureus due to CFX. The overall results show a modified release of ciprofloxacin with an effective antibacterial activity, giving the way for a new ciprofloxacin drug delivery system using Bana clay as carrier.
\end{abstract}

\section{Keywords}

Antibacterial Effect, Drug Delivery System, Clay, Ciprofloxacin, Intercalation

\section{Introduction}

Smectites are clay minerals used in various fields including petrol drilling, soil 
stabilization or pharmaceutical sciences [1] [2] [3] [4] [5]. Their excellent sorption capacity, high cation exchange ability, low toxicity and low price justify the interest to their use as carriers of active substances. [6] Their lamellar structures mainly favour their capacity to accommodate guests organic compounds and thus to form a range of so-called intercalated compounds. The fact that the release of active substances from these compounds is potentially controllable, justifies that these have been for years used by researchers in the development of drug delivery systems (DDS). [7] [8] Among the approaches proposed to synthetize drug delivery systems, ion exchange process has received considerable attention. [9] The synthesis of a delivery system for vitamin $B_{1}$ and timolol maleate has been successfully performed using montmorillonite as carrier. [7] [8] The oral bioavailability of the most potent antioxidant, glutathion has been improved by intercalating the latter in montmorillonite. [10] Controlled release venlafaxine hydrochloride has been successfully prepared from montmorillonite as host to delay its release. [2] Some studies indicate that Ciprofloxacin well adsorbed-desorbed on montmorillonite. [11] [12] The antibiotic activity of Ciprofloxacin sorbed by montmorillonite in satured porous media was studied and the results suggested that montmorillonite with high Ciprofloxacin sorption ability can act as carrier [13]; composite montmorilonite-Ciprofloxacin has shown an antibacterial activity on some common skin bacteria. [14] Good results were obtained in the synthesis of drug delivery system with montmorillonite as carrier of Ciprofloxacin. [15] Ciprofloxacin intercalated perfectly in montmorillonite with a sustained release over time; [16] and gentamicin is intercalated in montmorillonite and showed that the product can be used for control release of gentamicin. [17]

Ciprofloxacin is an antibiotic of fluoroquinolone class with a broad-spectrum of antimicrobial activity against gram (+) and gram (-) bacteria. Generally used for the treatment of respiratory, urinary and gastrointestinal infections, ciprofloxacin has a half-life of 4 to 5 hours. [18] The effect of an active substance depends on the sufficient concentration that reaches the site of action; in that way, the development of a modified form of ciprofloxacin (CFX) would improve its efficiency by maintaining plasmatic concentration to the desire level for long time, reduce undesirable effects, ameliorate comfort and observance of patient, reduce repetitive daily doses and protect CFX. Ciprofloxacin being an ampholyte is a good molecule for experimental elaboration of modified released system in the way that its release could be studied in large range of $\mathrm{pH}$. Note that, synthesis of CFX modified forms requires the choice an appropriate carrier that can easily accommodate CFX. As previously mentioned, smectite clays are good carriers of active substances. [11] [16] [17] In Bana, a locality of the western Cameroon, clay where identified as smectite and characterized. [19] This naturally occurring clay can gained improved value if they are successfully used as drug carrier. Hence, the aim of this study is to evaluate the potentiality of these smectite clays in the formulation of drug carrier systems.

To this end, ciprofloxacin has been choosen as the active substance and will be 
used for intercalation in coarse and fine fractions of the Bana clay. The composite CFX-clay have been subjected to physicochemical characterizations using Xray Diffractometry (XRD), Fourier-Transformed Infrared spectrometry (FTIR), Thermo-gravimetry analysis (TGA) and Brunner-Elmet-Teller analysis (BET). Thereafter, in vitro release of CFX and bacteriological effects of the composite CFXclays on two bacteria, Escherichia coli and Staphylococcus aureus, have been evaluated.

\section{Materials and Methods}

\subsection{Materials}

The clayey material was collected at $11.50 \mathrm{~m}$ depth at Bana $\left(5^{\circ} 84 \mathrm{E}-5^{\circ} 1 \mathrm{~N}\right)$, locality of the western region of Cameroon. Characterizations of this clay were carried out in previous work by Mache. [19] Bana clay mineralogy is constituated by montmorillonite $(74 \%)$, mica $(7.2 \%)$, kaolinite $(4.1 \%)$, quartz $(2.6 \%)$ and feldspar (5.9\%). Electrokinetic and $\mathrm{pH}$ measurements indicate that Bana clay is negatively charged in the range of $\mathrm{pH} 2$ - 10. Ciprofloxacin or 1-(cyclopropyl)-6fluoro-4-oxo-7-(piperazin-1-yl)-1,4-dihydroquinoline-3-carboxylic acid powder (Ciflox) molecular weight $331.4 \mathrm{~g} / \mathrm{mol}$ with purity of $98.0 \%$, chlorhydrated ciprofloxacin (molecular weigth $367.9 \mathrm{~g} / \mathrm{mol}$ ) respectively provided by Sigma Adlrich and Fagron, sodium chloride, silver nitrate, hydrochloric acid, phosphate buffer salt provided by Sigma-Aldrich.

Ciprofloxacin (CFX) is a zwitterion that presents two acid constants $\mathrm{pKa}_{1}$ (5.9) and $\mathrm{pKa}_{2}$ (8.8) because of the presence of the carboxylic and amine groups respectively. The cationic form $\mathrm{CFX}^{+}$is predominant when the $\mathrm{pH}$ is below 5.9 while the anionic form $\mathrm{CFX}^{-}$is dominant above $\mathrm{pH}$ 8.8. The neutral form $\mathrm{CFX}^{0}$ is dominant between $\mathrm{pH} 5.9$ and 8.8. [20] Hence, to take advantage of the cationic form in cationic exchange process in presence of clay, working at $\mathrm{pH}<5.9$ is justified.

\subsection{Methods}

\subsubsection{Clay Treatment}

The raw sampled clay was wet sieved at $40 \mu \mathrm{m}$, air-dried, crushed and sieved at $40 \mu \mathrm{m}$ to give $\mathrm{BN}$ (Bana). The capacity to be exchange of cations in the interlayer space of smectic clays depends on its hydratation degree; this later itself depends on ionic ray. The most the cation has a small ionic ray, the most its exchange is easy. After Lithium, $\mathrm{Na}^{+}$has a small ray and literature suggest that its echangeability by others cations will be easy. [7] We proceed to Na-saturation of Bana to maximise intercalation and release of Ciprofloxacin. $40 \mathrm{~g}$ of $\mathrm{BN}$ were introduced into $240 \mathrm{ml}$ of $1 \mathrm{M} \mathrm{NaCl}$ and then stirred for 8 hours; operation was repeated four times. Then repeated washing with deionized water and centrifugations at $3500 \mathrm{rpm}$ for $40 \mathrm{~min}$ was carried out until the supernatant water is free of chloride ions as tested with silver nitrate solution. The obtained cake is dried in oven at $105^{\circ} \mathrm{C}$ for 24 hours, crushed and sieved at $40 \mu \mathrm{m}$ to give BNNa (Bana satu- 
rated with $\mathrm{Na}^{+}$). For being around the clay fraction, with an assay of elimination of non-clay fraction, an extraction of the $\leq 2 \mu \mathrm{m}$ has been done. Another 40 grams of $\mathrm{BN}$ were also saturated with $\mathrm{NaCl}$ and introduced into $200 \mathrm{~mL}$ test tubes containing deionized water; thereafter, $\leq 2 \mu \mathrm{m}$ particles was extracted after sedimentation pre-calculated time according to the Stockes' law. [21] [22] The suspension obtained undergoes extensive centrifugations at $3500 \mathrm{rpm}$ for 1 hour; the slurry is dried at $105^{\circ} \mathrm{C}$ for $10 \mathrm{~h}$, ground and sieved at $40 \mu \mathrm{m}$ to obtain $\mathrm{BNNa}$ $\mathrm{F}$ (fine fraction of Bana preceded by $\mathrm{Na}^{+}$saturation).

\subsubsection{Preparation of Loaded Clay-CFX Materials}

As quoted in section 2.1, CFX positive form is achieved at $\mathrm{pH}<5.9$; hence, the intercalation was implemented in batch mode at room temperature in a $10^{-2} \mathrm{M}$ $\mathrm{HCl}$ with an average medium $\mathrm{pH}$ of 2.5. In view to optimize the process, contact time and the initial amount of CFX effect have been calculated; the various operations during the test were replicates three times.

\section{1) Variation of the contact time}

The effect of the stirring time on the amount of adsorbed CFX is evaluated by introducing $100 \mathrm{mg}$ of $\mathrm{BN}, \mathrm{BNNa}$ or $\mathrm{BNNa}-\mathrm{F}$ in $50 \mathrm{~mL}$ of CFX $600 \mathrm{mg} / \mathrm{L}$ under a stirring of 500 rotations per minute (rpm) with stirring times between 5 and $240 \mathrm{~min}$. At each time, pre-calculated volume of solution is collected, filtered through PTFE (polytetrafluoroethylene) filters of $0.2 \mu \mathrm{m}$ and then diluted for the determination of the equilibrium (residual) amount of CFX by using UV-visible spectrophotometry at $\lambda_{\max }=277 \mathrm{~nm}$.

\section{2) Adsorption isotherms}

$150 \mathrm{mg}$ of $\mathrm{BN}, \mathrm{BNNa}$ or $\mathrm{BNNa}-\mathrm{F}$ are introduced into $50 \mathrm{ml}$ of CFX concentrations range 200 to $1000 \mathrm{mg} / \mathrm{L}$. The mixture is stirred at $500 \mathrm{rpm}$ for equilibrium contact time at room temperature and samples are filtered through PTFE filters of $0.2 \mu \mathrm{m}$. Maximum amount of CFX adsorbed is determined by measuring residual CFX using UV-visible spectrophotometry at $\lambda_{\max }=277 \mathrm{~nm}$.

\subsubsection{Characterizations of Raw and Loaded Compounds}

Characterizations will approve the smectitic nature of the materials used and confirm CFX intercalation.

$\mathrm{X}$-ray diffractometry (XRD) was performed on powders using a Bruker diffractometer under the following conditions: $\mathrm{CuKa}$ radiation, $40 \mathrm{KV}$ voltage, 40 $\mathrm{mA}$ intensity and scanning angle from $3^{\circ}$ to $70^{\circ}$ by steps of $0.02^{\circ}$ with a duration of $1 \mathrm{~s}$.

Fourier-transform infrared spectroscopy (FTIR) was performed in ATR mode at $4000-600 \mathrm{~cm}^{-1}$ on ZnSe crystal using a PerkinElmer infrared spectrophotometer.

The thermo-gravimetric analysis (TGA) was carried out using thermo-gravimeter Q5000 between $20^{\circ} \mathrm{C}$ and $800^{\circ} \mathrm{C}$ under an oxygen atmosphere at a heating rate of $5^{\circ} \mathrm{C} / \mathrm{min}$ and a flow rate of $25 \mathrm{~mL} / \mathrm{min}$ of oxygen.

The specific surface areas of the samples were determined from nitrogen adsorption and desorption isotherms at $77 \mathrm{~K}$, obtained from Micrometrics TriStar 
II 3020 V1. The specific surface area (SSA) was calculated from adsorption data by applying the Brunauer-Emmet-Teller (B.E.T) method, which only measures the external surface accessible by molecules.

\subsection{UV-Visible in vitro Release Evaluation}

In vitro release studies have been carried out in phosphate buffered saline media of $\mathrm{pH} 7.4$ and simulated gastric fluid at $\mathrm{pH} 1.16$ in static mode. $10 \mathrm{mg}$ of clayCFX in $100 \mathrm{~mL}$ of buffer solution was taken in a thermo shaker at $37^{\circ} \mathrm{C}$ with shaking frequency about $100 \mathrm{rpm} .5 \mathrm{ml}$ of sample was withdrawn at regular time intervals and the same volume was replaced with a fresh dissolution medium. Samples were analyzed for CFX content by UV spectrophotometer at $\lambda_{\max }=270$ and $277 \mathrm{~nm}$. These studies have been performed in triplicate for each sample and the average values were reported.

\subsection{Bacteriological Studies}

\subsubsection{Release Studies Using High Liquid Performance Chromatography (HPLC)}

$\mathrm{BN}, \mathrm{BNNa}, \mathrm{BN}-\mathrm{CFX}$ and $\mathrm{BNNa}-\mathrm{CFX}$ samples are sterilized under $\mathrm{UV}$ radiation for $15 \mathrm{~min}$; the samples $(5 \mathrm{mg}$ ) were released in $10 \mathrm{~mL}$ of PBS, under agitation at $80 \mathrm{rpm}$ at $37^{\circ} \mathrm{C}$. At times $1 \mathrm{~h}, 2 \mathrm{~h}, 4 \mathrm{~h}, 6 \mathrm{~h}, 24 \mathrm{~h}, 48 \mathrm{~h}, 72 \mathrm{~h}, 96 \mathrm{~h}$, the media of each well is taken by syringe and filter needle (BD Blunt filter Needle, Beckton Dickinson). The collected medium is renewed by $10 \mathrm{~mL}$ of fresh PBS, using the needle that was used to rinse it, and restocked to $80 \mathrm{rpm}$ at $37^{\circ} \mathrm{C}$. Samples were analyzed for CFX content by HPLC at $\lambda_{\max }=270 \mathrm{~nm}$. These studies were performed in triplicate for each sample and the average values were reported.

The sample mediums (BN, BNNa, BN-CFX and BNNa-CFX) have been analyzed in microbiology by a diffusion test.

\subsubsection{Bacteriological Sample Preparation}

$9 \mathrm{~mm}$ diameter Petri dishes containing $18 \mathrm{~mL}$ Muller Hinton Agar are seeded with $0.1 \mathrm{~mL}$ of bacterial suspension at $10^{4} \mathrm{cfu} / \mathrm{mL}$ (E. coli $\mathrm{K} 12$ or S. aureus CIP224). Carrots of $6 \mathrm{~mm}$ diameter are made in the agar to obtain wells allowing the deposit of $50 \mu \mathrm{L}$ of solution to be tested.

\subsubsection{Methodology}

Petri dishes are incubated at $37^{\circ} \mathrm{C}$ for 24 hours. After $24 \mathrm{~h}$ of incubation, the seeded bacteria yielded a homogeneous bacterial mat, and the solutions provided an inhibition zone with a diameter related to the amount of active ingredient contained in the solution tested. The diameter of these inhibition zones is measured, and graphically expressed over time.

\section{Results and Discussion}

\subsection{Raw Clays and Clay-CFX Loaded Compounds Characterizations}

\subsubsection{X-Ray Diffractometry (XRD)}

Figure 1 shows the X-ray patterns of clays with basal reflection $\mathrm{d}_{001}$ at $14.10 \AA$, 


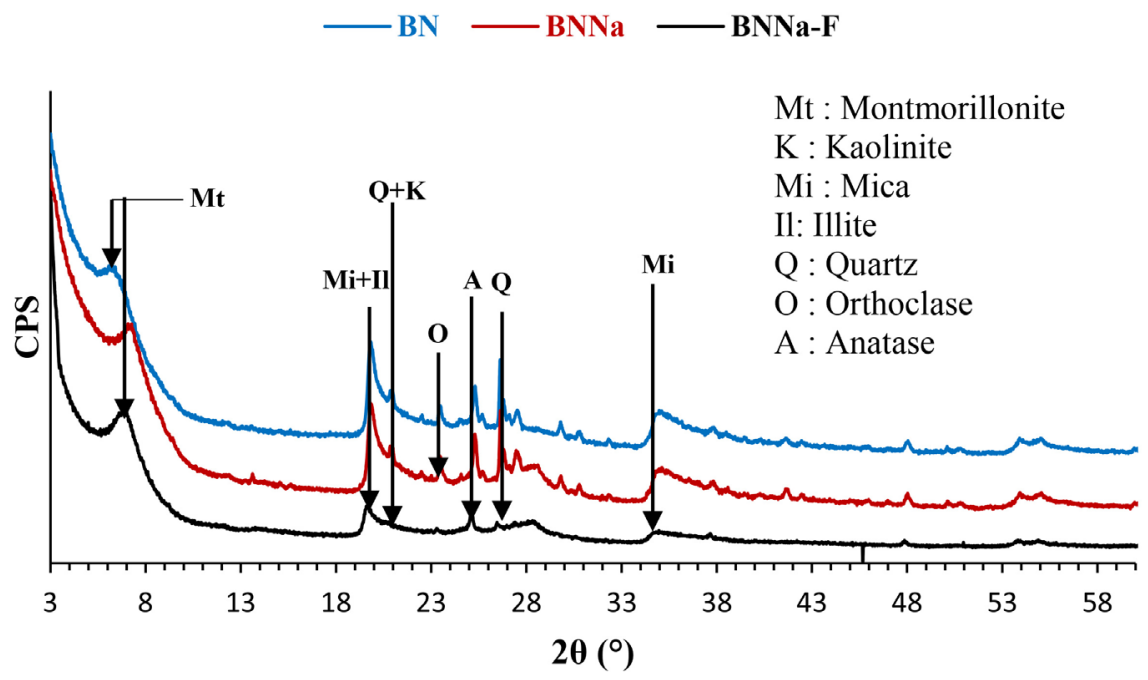

Figure 1. X-ray patterns of raw materials.

$12.33 \AA$ and $12.41 \AA$ respectively for $\mathrm{BN}, \mathrm{BNNa}, \mathrm{BNNa}-\mathrm{F}$ assigned to montmorillonite. [23] The difference between basal reflections at $14.10 \AA$ of $B N$ with 12.33 or $12.41 \AA$ of $\mathrm{BNNa}$ and BNNa-F could be explained by hydrated radius of naturally intercalated cations of $\mathrm{BN}$ in comparison of $\mathrm{Na}^{+}$in homoionic forms. Associated minerals are kaolinite (7.20 ̊), mica (4.47 $)$ ), quartz (3.34 $)$ ), anatase $(3.51 \AA)$ and orthoclase (3.78 $\AA$ ). [19] [24] BNNa-F associated mineral are less important probably due to their elimination during the process of fine fraction extraction. BN, BNNa and $\mathrm{BNNa}-\mathrm{F}$ are smectites clays according to their $\mathrm{X}$ ray patterns. [19]

Figure 2 below presents the visual aspect of Clay-CFX loaded compounds prepared; this aspect is similar to clay mineral.

In Figure 3, it can be clearly seen that basal distance at $14.10 \AA$ of $B N$ rises to $15.71 \AA$ for $\mathrm{BN}-\mathrm{CFX}$, the one at $12.33 \AA$ of $\mathrm{BNNa}$ rises to $16.01 \AA$ for BNNa-CFX and that at $12.41 \AA$ of BNNa-F rises to $16.52 \AA$ for BNNa-F-CFX. The increase of basal spacing could be due to intercalation of CFX by ionic exchange between the hydrated interlayer cations of clays and CFX molecules [11]. The increase in the basal distance for clay-CFX is $1.61 \AA, 3.68 \AA$ and $4.11 \AA$ respectively for $\mathrm{BN}-\mathrm{CFX}, \mathrm{BNNa}-\mathrm{CFX}$ and BNNa-F-CFX. BNNa and BNNa-F possess in their interlayer a more readily exchangeable cation $\mathrm{Na}^{+}$, while the raw $\mathrm{BN}$ may have more tightly linked cations in its interlayer that could limit the CFX intercalation because $\mathrm{Na}^{+}$favours ionic exchange in interlayer space. Cationic exchange capacity (CEC) represents the ionic capacity of interlayer cations to be exchange by others cations and Na-saturation of clay increase this CEC. [8] So, after $\mathrm{Na}$-saturation, $\mathrm{CEC}$ of $\mathrm{BNNa}$ and BNNa-F become certainly high than raw $\mathrm{BN}$ cationic capacity exchange. Which precede could be explain the higher basal spacing variation after CFX loading of $\mathrm{BNNa}$ and $\mathrm{BNNa}-\mathrm{F}$ than $\mathrm{BN}$. The thickness of montmorillonite sheet is $10 \AA$ [25] and the theoretical estimated value of longitudinal molecular length of CFX is $8.5 \AA$ while its lateral molecular length of CFX is $11.9 \AA$ [16]. The interlayer space represents the basal spacing minus 


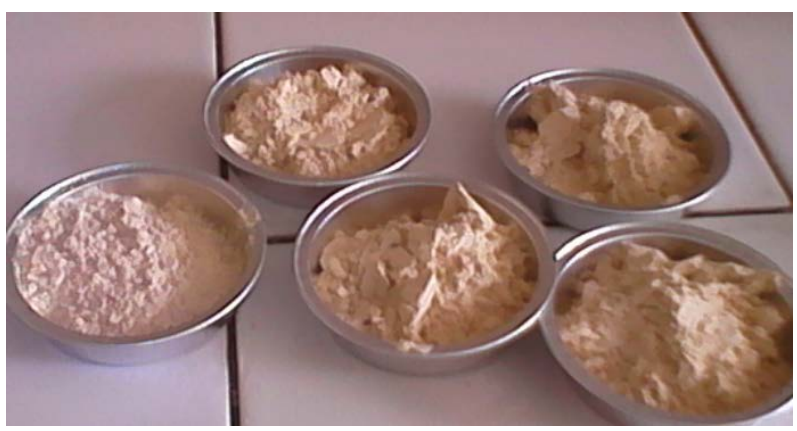

Figure 2. Visual aspect of clay-CFX loaded compounds.

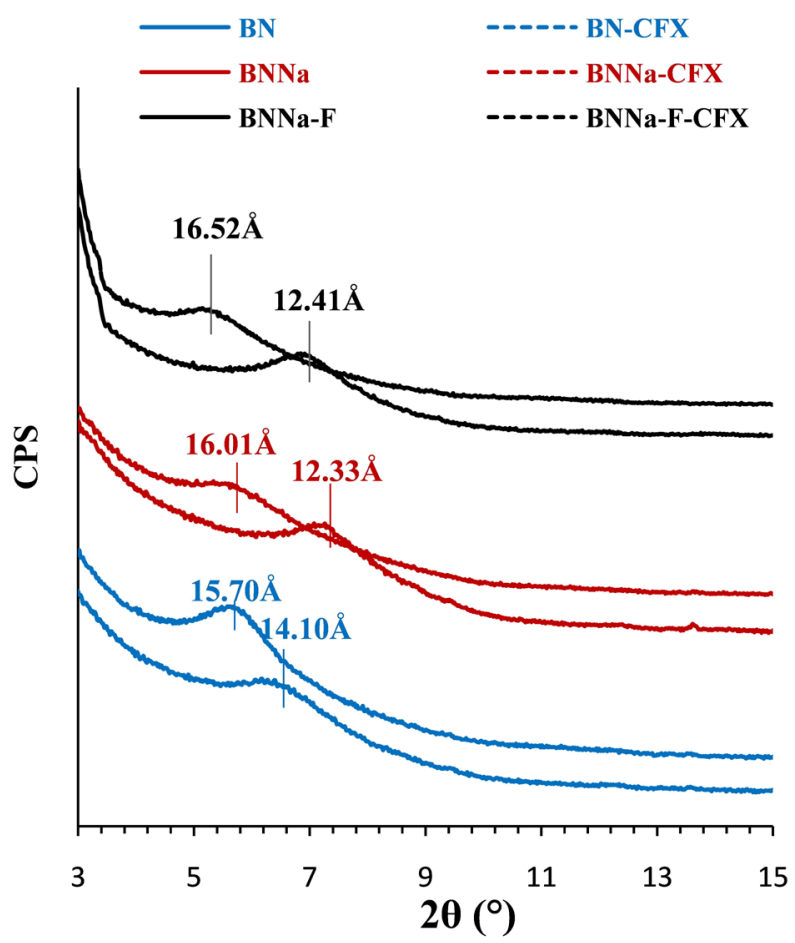

Figure 3. Basal distance change between raw samples and their clay-CFX forms.

the layer thick. The experimental values of interlayer space of BN-CFX, BNNaCFX, BNNa-F-CFX are $5.71 \AA, 6.01 \AA$ and $6.52 \AA$ respectively. Those values are smaller than the theoretical estimated value of longitudinal molecular length of CFX (8.5 ̊). This presumes that after intercalation, CFX in interlayer space has been compressed by electrostatic interactions in clays. [16] The variation of the basal spacing, indicative of CFX intercalation within the clay platelets will be confirm by infrared spectroscopy results.

\subsubsection{Fourier-Transform Infrared Spectroscopy (FTIR)}

Figure 4 shows the infrared spectra of BN, BNNa, BNNa-F (a), CFX (b and c). From raw material spectra (Figure 4(a)), the vibration band at $3700 \mathrm{~cm}^{-1}$ corresponds to the elongation vibration of the $-\mathrm{OH}$ bond characteristic of phyllosilicate. [26] The band at $3623 \mathrm{~cm}^{-1}$ is characteristic of internal -OH clays structure and particularly for kaolinite. The $3381 \mathrm{~cm}^{-1}$ band corresponds to the stretching 


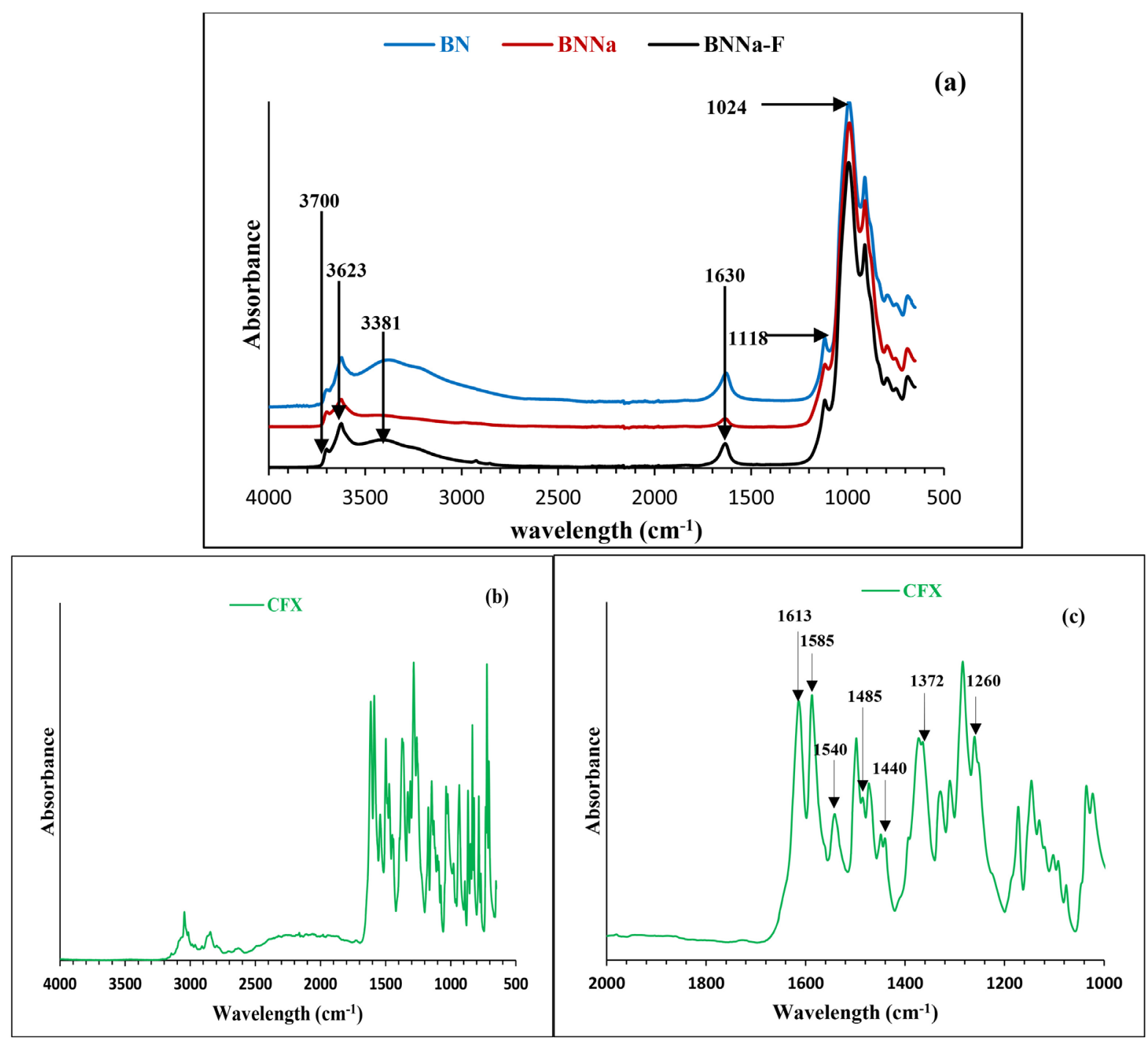

Figure 4. IR spectra of (a) BN, BNNa, BNNa-F; (b) CFX; (c) CFX zooming between $2000-1000 \mathrm{~cm}^{-1}$.

vibration of $-\mathrm{OH}$ bond of hydration water; this band is better defined in $\mathrm{BN}$ than $\mathrm{BNNa}$ or BNNa-F because in those latter, some water molecules were displaced during saturation with $\mathrm{NaCl}$. The peak at $1630 \mathrm{~cm}^{-1}$ is attributed to in plane deformation of adsorbed water molecule. The bands at $1118 \mathrm{~cm}^{-1}$ and $1024 \mathrm{~cm}^{-1}$ are for stretching vibrations Si-O bond of phyllosilicates. [10] [27]

In Figure 4(b) and Figure 4(c), important CFX characteristic bands are mostly between $1700 \mathrm{~cm}^{-1}$ and $1200 \mathrm{~cm}^{-1}$. The band at $1613 \mathrm{~cm}^{-1}$ corresponds to $\mathrm{C}=\mathrm{O}$ bond of quinolones and peak at $1585 \mathrm{~cm}^{-1}$ is due to asymmetric stretching vibration of $\mathrm{COO}^{-}$bond; peak at $1540 \mathrm{~cm}^{-1}$ is attributed to stretching vibration of aromatic $\mathrm{C}=\mathrm{C}$. Bands at $1485 \mathrm{~cm}^{-1}$ and $1440 \mathrm{~cm}^{-1}$ represent respectively stretching vibration of C-N and inclination vibration of -C-H or -C-O. Peak at 1372 $\mathrm{cm}^{-1}$ corresponds to protonation of amino group in piperazine part. The 1260 $\mathrm{cm}^{-1}$ band is assigned to the coupling of $-\mathrm{C}-\mathrm{O}$ elongation vibration with $\mathrm{O}-\mathrm{H}$ deformation of COOH. [28] [29] [30] 
Due to the similarity among the IR spectra of all loaded compounds, only $\mathrm{BNNa}-\mathrm{F}$ spectra and its loaded compounds BNNa-F-CFX have been presented in Figure 5 together with that of CFX. For better visualization of changes occurred, spectra have been zoomed in CFX functional domain $2000-1000 \mathrm{~cm}^{-1}$. On the spectra of loaded materials, appearance of new bands is observed. The peak at $1613 \mathrm{~cm}^{-1}\left(\mathrm{C}=\mathrm{O}\right.$ stretching vibration) of CFX shifted to $1630 \mathrm{~cm}^{-1}$ and mix up with the one (-OH inclination vibration) already presents in clay. This mixing made the peak more intense. Also, the shifting from $1613 \mathrm{~cm}^{-1}$ in CFX to $1630 \mathrm{~cm}^{-1}$ in the loaded sample is associated to strong interactions between $\mathrm{C}=\mathrm{O}$ of CFX and the oxygen atoms of the basal surface of the clay materials. [31] The vibration at $1580 \mathrm{~cm}^{-1}$ attributed to carboxylate $\mathrm{COO}^{-}$disappears after adsorption certainly because of the loaded compounds elaboration conditions $(\mathrm{pH}<$ 5.9) which induce the cationic form of CFX. The band at $1540 \mathrm{~cm}^{-1}$ is attributed to stretching vibration of aromatic $\mathrm{C}=\mathrm{C}$; peaks at 1485 and $1460 \mathrm{~cm}^{-1}$ designer respectively stretching vibration of $\mathrm{C}-\mathrm{N}$ and inclination vibration of $-\mathrm{C}-\mathrm{H}$ or -C-O. The displacement of the protonation vibration of amino group from 1372 $\mathrm{cm}^{-1}$ to $1386 \mathrm{~cm}^{-1}$ suggests existence of electrostatic attractions between protonated amino group and negative surface charges. The $1260 \mathrm{~cm}^{-1}$ band moves to $1273 \mathrm{~cm}^{-1}$ because of the strong hydrogen bonds between $\mathrm{COOH}$ and the hydroxyl surface group of montmorillonite in an acidic medium. [11]

The appearance of CFX characteristic bands on the loaded compounds proves the CFX adsorption on the raw materials and indicates intercalation of CFX in the interlayer space of raw materials.

\subsubsection{Thermogravimetric Analysis (TGA)}

Figure 6 (a) shows dTG/TG curves of clay materials. Between $20^{\circ} \mathrm{C}$ and $150^{\circ} \mathrm{C}$, mass loss of $12.11 \%, 4.8 \%$ and $8.5 \%$ respectively for $\mathrm{BN}, \mathrm{BNNa}, \mathrm{BNNa}-\mathrm{F}$ is attributed to loss of water moisture and water bound to interfoliar cations. [32] This loss is lower in Na-saturated materials than $\mathrm{BN}$ because of reduced intercalated water molecules as proposed from XRD. Around $430^{\circ} \mathrm{C}$ for $\mathrm{BN}, 470^{\circ} \mathrm{C}$ for

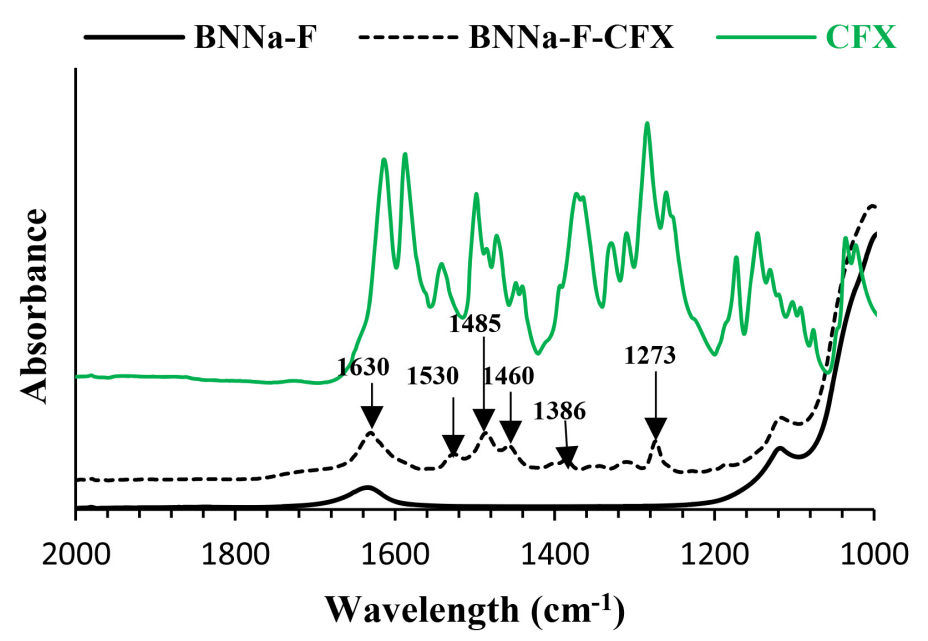

Figure 5. IR spectra of BNNa-F, BNNa-F-CFX and CFX $\left(2000-1000 \mathrm{~cm}^{-1}\right)$. 


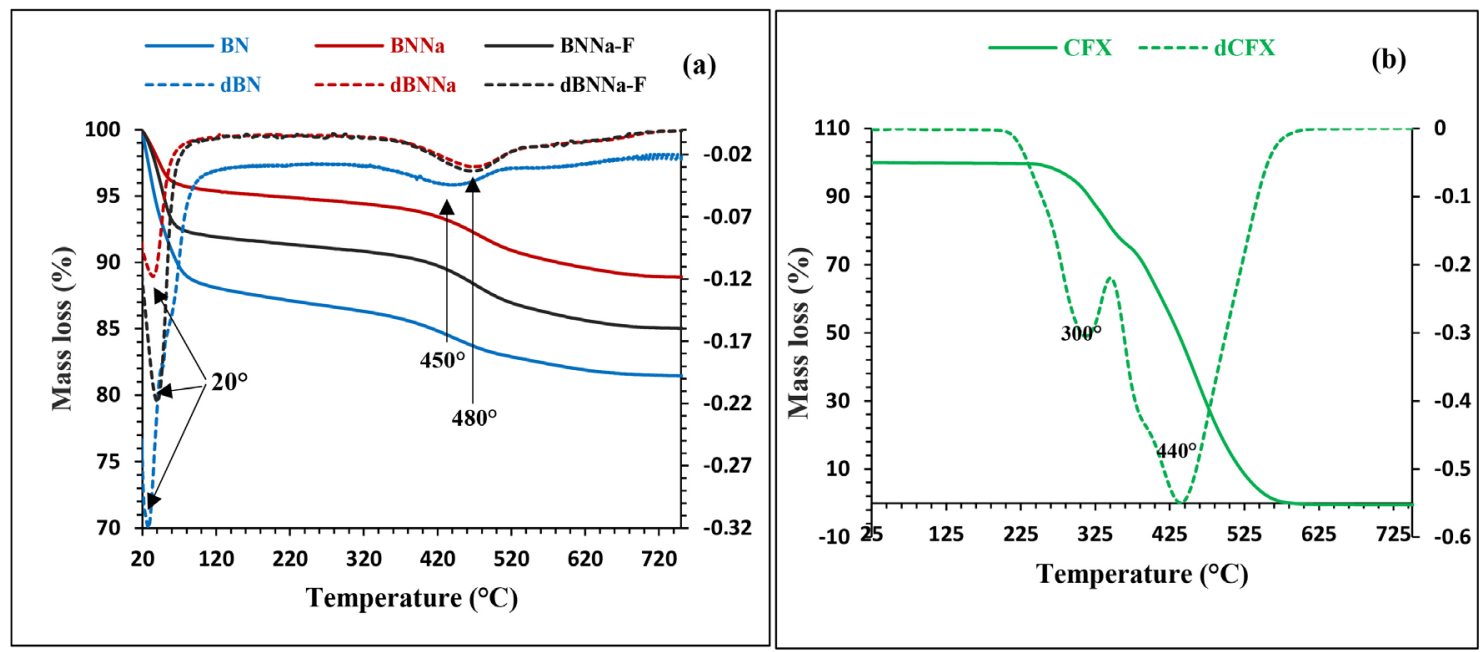

Figure 6. dTG/TG curves of (a) BN, BNNa, BNNa-F; (b) CFX.

$\mathrm{BNNa}$ and $\mathrm{BNNa}-\mathrm{F}$ respectively, a maximum mass loss of $6.3 \%, 6.4 \%$ and $6.4 \%$ correspond to de-hydroxylation of clay minerals up to $700^{\circ} \mathrm{C}$. [32] The mass loss is almost the same, which means that clay content in the prepared materials have the same structure. For CFX (Figure 6(b)), it is observed that maximum decomposition occurred at two different temperatures $\left(300^{\circ} \mathrm{C}\right.$ and $\left.400^{\circ} \mathrm{C}\right)$. It is proposed that at $300^{\circ} \mathrm{C}$ the less stable functions such as carboxylic and amino-basic are decomposed and the most stable phenyl cycle are decomposed later around $400^{\circ} \mathrm{C}$

Figures 7(a)-(c) show the dTG/TG curves of clay-CFX materials. The CFX decomposition is marked by two peaks temperature around $300^{\circ} \mathrm{C}$ and around $400^{\circ} \mathrm{C}\left(413^{\circ} \mathrm{C}, 395^{\circ} \mathrm{C}, 420^{\circ} \mathrm{C}\right.$ respectively for BN-CFX, BNNa-CFX and BNNa-FCFX). Those two stages of decomposition are observed for pure CFX (see Section 3.1.3-c). Around $300^{\circ} \mathrm{C}$, decomposition of CFX is accompanied by mass loss of $17 \%, 18 \%$ and $19.5 \%$ respectively for BN-CFX, BNNa-CFX and BNNa-F-CFX; finally, around $560^{\circ} \mathrm{C}$, mass loss could be due to complete disintegration of CFXclay structure. [1]

The comparison of the mass loss is coherent with the observed changes in basal distance from XRD which indicates increase intercalation as follow BNNaF-CFX > BNNa-CFX > BN-CFX. The same temperature of CFX-clay structure disintegration $\left(560^{\circ} \mathrm{C}\right)$ suggests that $\mathrm{BN}-\mathrm{CFX}, \mathrm{BNNa}-\mathrm{CFX}$ and $\mathrm{BNNa}-\mathrm{F}-\mathrm{CFX}$ have the same structure.

As the total mass loss can be associated to CFX decomposition, the estimation of CFX mass loss at $700^{\circ} \mathrm{C}$ was calculated. The experimental CFX quantities have been compared to UV estimation of CFX fixed by the clay. In this way, $146 \mathrm{mg} / \mathrm{g}$, $153.4 \mathrm{mg} / \mathrm{g}, 156.9 \mathrm{mg} / \mathrm{g}$ of CFX adsorbed obtained by UV estimation respectively for BN-CFX, BNNa-CFX, BNNa-F-CFX is closed to $133.5 \mathrm{mg} / \mathrm{g}, 147.4 \mathrm{mg} / \mathrm{g}$, $150.7 \mathrm{mg} / \mathrm{g}$ of CFX adsorbed calculated by TGA methods. The obtained results are in agreement and the UV-visible values can be use latter for others calculations. 

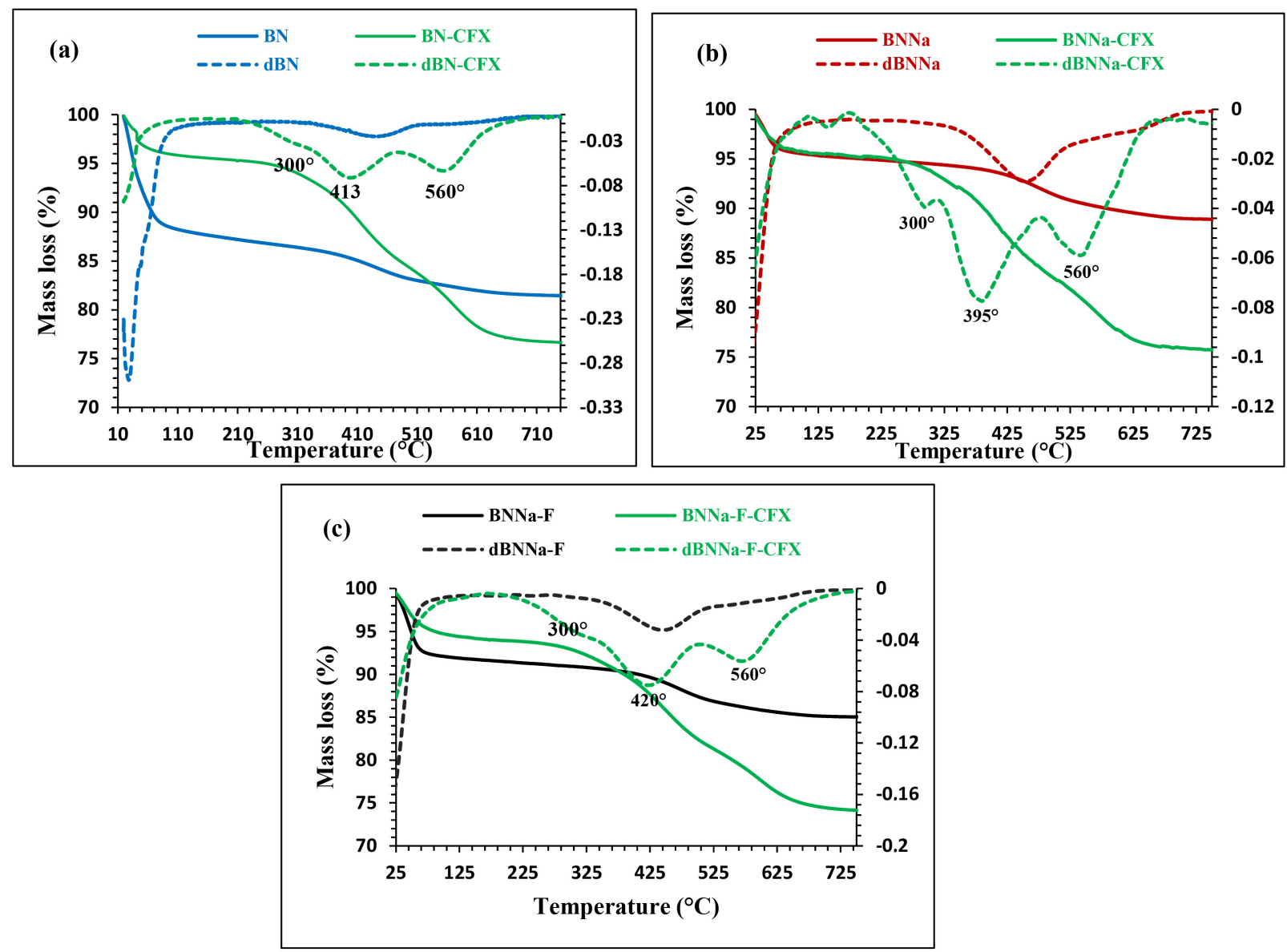

Figure 7. dTG/TG curves of (a) BN and BN-CFX; (b) BNNa and BNNa-CFX; (c) BNNa-F and BNNa-F-CFX.

\subsubsection{Adsorption-Desorption Isotherm and BET Surface Area}

The $\mathrm{N}_{2}$ adsorption-desorption isotherms of the natural clays on Figure 8 show very similar shapes with presence of a hysteresis that indicates existence of mesopores. [19] The measured specific surface area of BN, BNNa, BNNa-F were about $39.3 \mathrm{~m}^{2} / \mathrm{g}, 42.8 \mathrm{~m}^{2} / \mathrm{g}, 50.1 \mathrm{~m}^{2} / \mathrm{g}$ respectively. The high value for BNNa-F could be explained by the fact that this sample in the fine fraction is enriched in clay minerals. Those values of the specific surface area (SSA) are confirms the high smectite mineral content in clay. The high SSA area is important factor when the clay minerals are used in adsorption experimentations. [19]

Only BNNa/BNNa-CFX adsorption-desorption shapes are reported for comparison. Measured specific area decreases from $42.8 \mathrm{~m}^{2} / \mathrm{g}$ for BNNa to $16 \mathrm{~m}^{2} / \mathrm{g}$ for BNNa-CFX apart of Figure 9; this decreasing could be attribute to occupation of BNNa-F pores by CFX molecules during adsorption process, expressive of CFX presence on loaded compounds.

\subsection{Optimisation of the Clay-CFX Preparation}

Figure 10(a) shows that uptake of CFX within the clay is rapid during the first 20 minutes and the equilibrium is reached after $30 \mathrm{~min}$. Equilibrium is quickly reached because of the smectitic nature of clays which favoured ionic exchange 

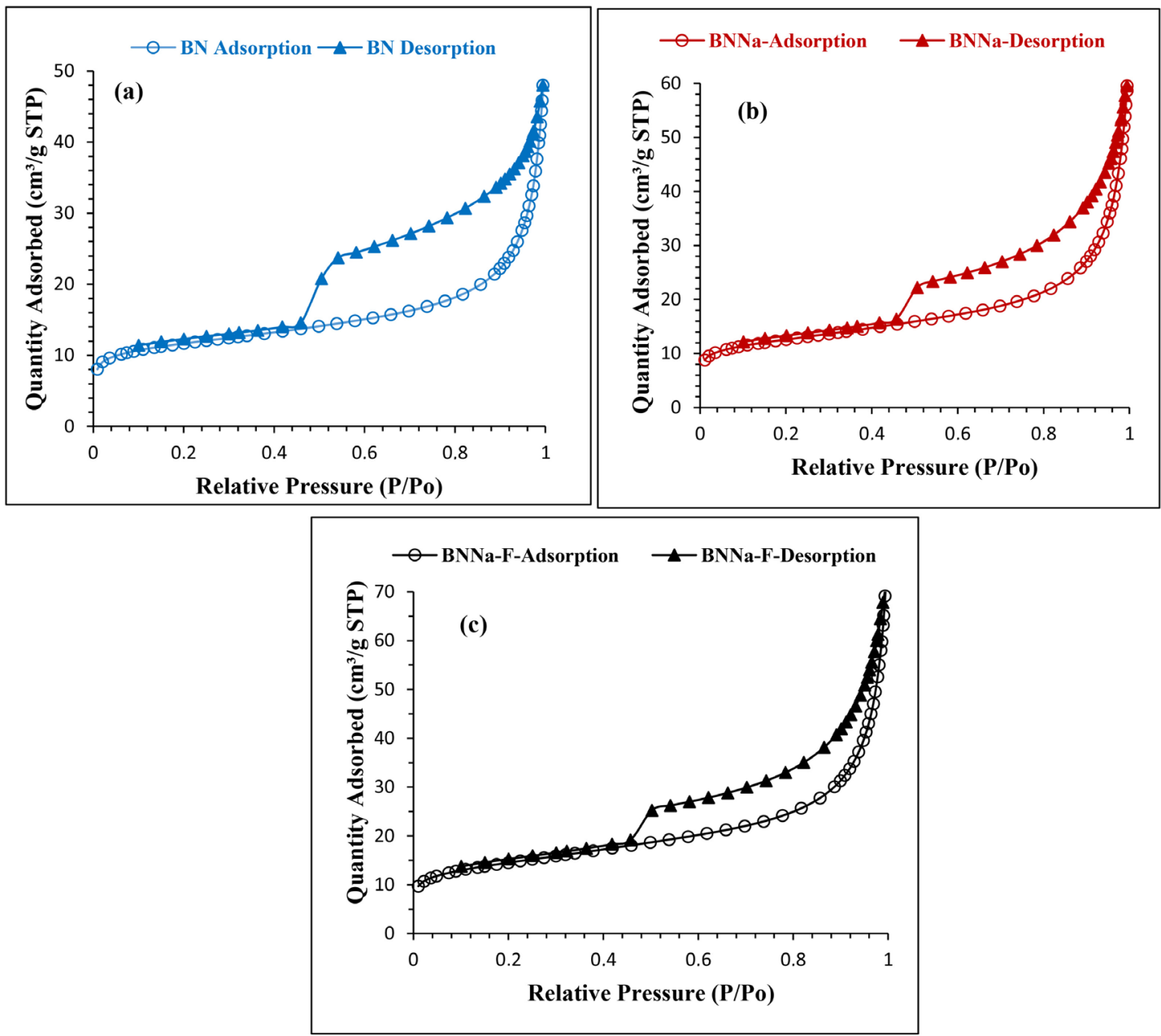

Figure 8. $\mathrm{N}_{2}$ adsorption-desorption isotherms of (a) BN; (b) BNNa; (c) BNNa-F. BN: raw sample; BNNa: Na-Homoionic coarse fraction of $40 \mu \mathrm{m}$; BNNa-F: Na-Homoionic form of the Fine fraction $(<2 \mu \mathrm{m})$.

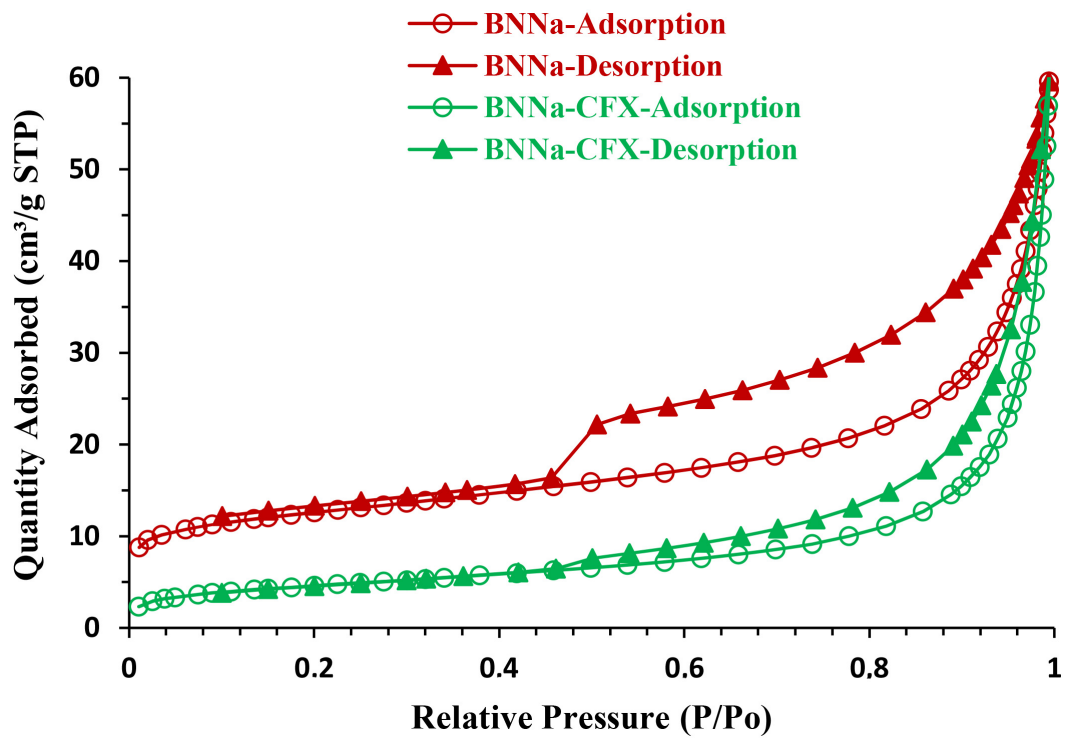

Figure 9. $\mathrm{N}_{2}$ adsorption-desorption isotherms of $\mathrm{BNNa}$ and BNNa-CFX. BNNa: Na-Homoionic form of BN; BNNa-CFX: CFX loaded on BNNa. 

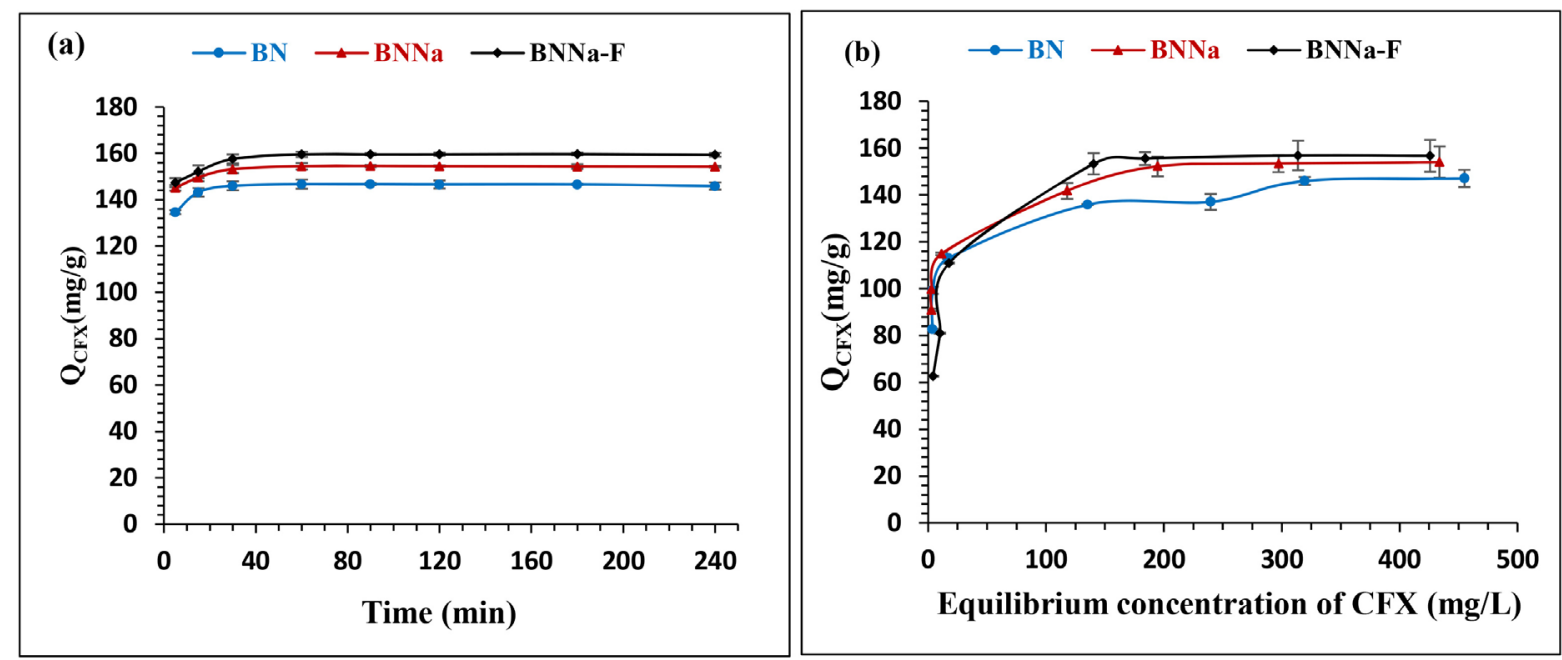

Figure 10. (a) Variation of the amount of CFX adsorbed as function of stirring time; (b) Change in amount of CFX fixed as function of equilibrium CFX concentration.

between $\mathrm{CFX}^{+}$and interlayer cations. [6] A contact time of $60 \mathrm{~min}$ is retained as optimal time for maximum intercalation of the CFX within the clay matrix.

In Figure 10(b), it is observed that the amount of intercalated CFX increases with the increasing of initial concentration of CFX until reaching an equilibrium amount of CFX equal to $146 \mathrm{mg} / \mathrm{g}, 153.4 \mathrm{mg} / \mathrm{g}, 156.9 \mathrm{mg} / \mathrm{g}$ respectively for $\mathrm{BN}$, $\mathrm{BNNa}$ and BNNa-F. These values are in agreement with specific surface areas values of the precursor clays $\left(39.3 \mathrm{~m}^{2} / \mathrm{g}, 42.8 \mathrm{~m}^{2} / \mathrm{g}, 50.1 \mathrm{~m}^{2} / \mathrm{g}\right.$ respectively for $\mathrm{BN}$, $\mathrm{BNNa}, \mathrm{BNNa}-\mathrm{F})$ which predicted that quantity of CFX intercalated will be in this order $\mathrm{Q}(\mathrm{BN})<\mathrm{Q}(\mathrm{BNNa})<\mathrm{Q}(\mathrm{BNNa}-\mathrm{F})$. For optimal intercalation using 1 $\mathrm{g}$ of the Bana clay, the CFX concentration should range between $200 \mathrm{mg} / \mathrm{L}$ to 300 $\mathrm{mg} / \mathrm{L}$.

\subsection{Release Profiles}

Figure 11(a) and Figure 11(b) show the release behaviors of CFX from clayCFX loaded compounds in PBS ( $\mathrm{pH} 7.4)$ and SG (pH 1.16) at $37^{\circ} \mathrm{C}$. CFX released have been measured at 270 and $277 \mathrm{~nm}$ in UV-visible spectrophotometer respectively for PBS and SG.

After 1 h, 3 h, 5 h, $7 \mathrm{~h}$ in PBS (Figure 11(a)), we observe a somewhat quick release $(\sim 13 \%, 22 \%, 28 \%, 30 \%)$ for BN-CFX, $(\sim 13 \%, 23 \%, 29 \%, 33 \%)$ for BNNaCFX and $(\sim 12 \%, 21 \%, 26 \%, 28 \%)$ for BNNa-F-CFX. After $7 \mathrm{~h}$, appears a continued and prolonged release up to $96 \mathrm{~h}(41 \%, 43 \%, 37 \%$ respectively for BN-CFX, BNNa-CFX and BNNa-F-CFX). Percentage of CFX released decreased in the order of $\mathrm{BNNa}-\mathrm{CFX}<\mathrm{BN}-\mathrm{CFX}<\mathrm{BNNa-F-CFX}$. This result was not attended because the CFX intercalated decreased in order BNNa-F-CFX $<$ BNNa-CFX $<$ BNCFX.

In SG buffer medium (Figure 11(b)), the release of CFX is very fast with $21 \%$, $21 \%, 24 \%$ respectively for BN-CFX, BNNa-CFX and BNNa-F-CFX after $1 \mathrm{~h}$ with an initial burst observed until $5 \mathrm{~h}$. This is followed by prolonged released of $\leq 31 \%$ 


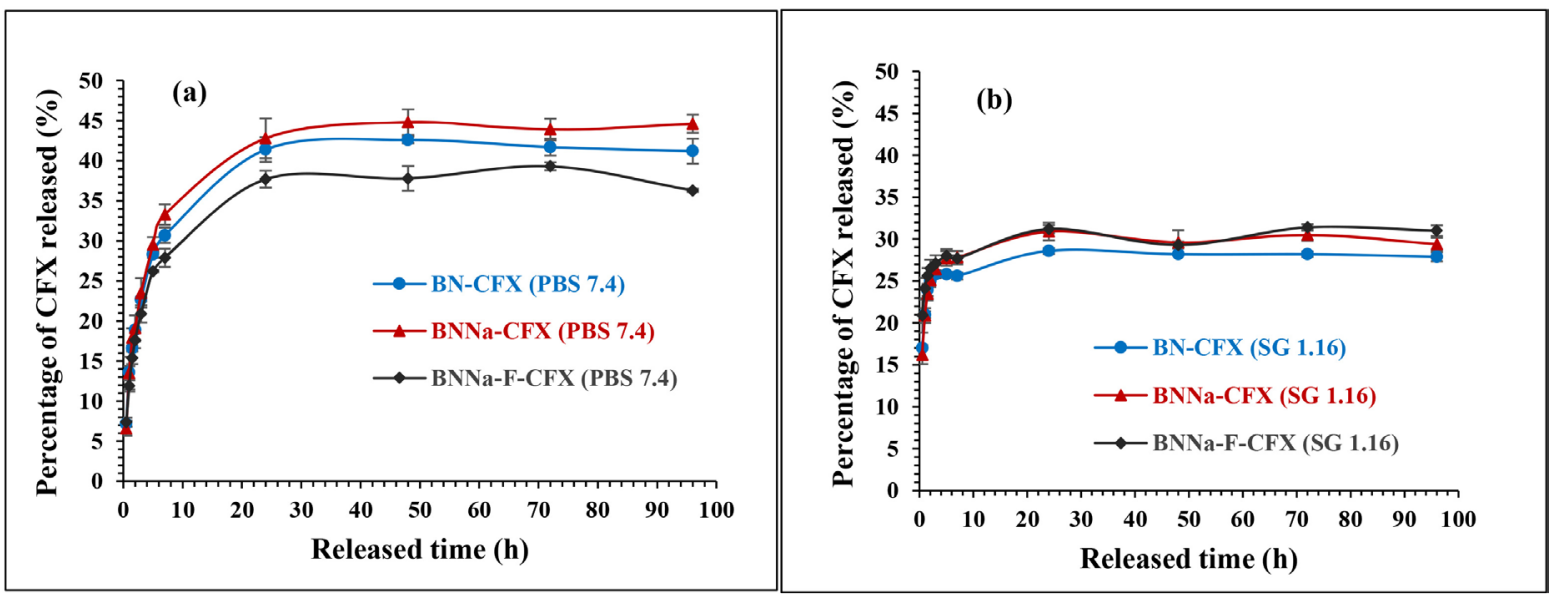

Figure 11. Release behavior of CFX from clay-hybrids compounds in: (a) PBS, pH 7.4 and (b) SG, pH 1.16 medium at $37^{\circ} \mathrm{C}$.

of CFX intercalated up to $96 \mathrm{~h}$. CFX released increased in order BN-CFX $<\mathrm{BNNa}$ CFX $<$ BNNa-F-CFX according to order of CFX intercalated increased BN-CFX $<$ BNNa-CFX $<$ BNNa-F-CFX.

The sustained release of CFX from clay-CFX loaded compounds may be due to de-intercalation of CFX intercalated from clay interlayers by ion exchange mechanism between CFX intercalated and buffer cations. [16] This ion exchange, which is an equilibrium phenomenon, may also be used to explain the first-time rapid release observed in PBS and SG mediums.

One observation that one can make is that, percentage of release for the both cases does not reach $100 \%$. As a matter of fact, IR spectra (Figure 12 of BN-CFX and R-BN-CFX-96h (BN-CFX residue sample after $96 \mathrm{~h}$ of release in SG), show that characteristic peaks of CFX have decreased in intensity but are still presents on R-BN-CFX; meaning that some CFX remains intercalated in clays. This can be explained by the fact that release process by ion exchange is an equilibrium phenomenon; in that way, all interlayers cations could not be completely exchanged. [33] Nonetheless, as we can see, for all loaded compounds, CFX released is faster in SG than PBS and those releases are prolonged and continued in the time.

\subsection{Bacteriological Effects of Raw and Clay-CFX Samples on Escherichia coli and Staphylococcus aureus}

Figure 13 presents HPLC results of CFX releases studies from BN-CFX and BNNaF-CFX clay-loaded compounds.

As the can be seen, CFX are continuously and progressively released over the time. So bacteriological assays can be done on those clay-loaded compounds.

Figures 14-16 present inhibition diameter of materials versus time, bacteriological results of raw clays (BN and $\mathrm{BNa}$ ) on Escherichia coli and bacteriological effect of loaded samples BN-CFX and BNNa-CFX (residue obtain after $96 \mathrm{~h}$ of release in PBS, pH 7.4) on Escherichia coli (E. coli) and Staphylococcus aureus (S. aureus). 


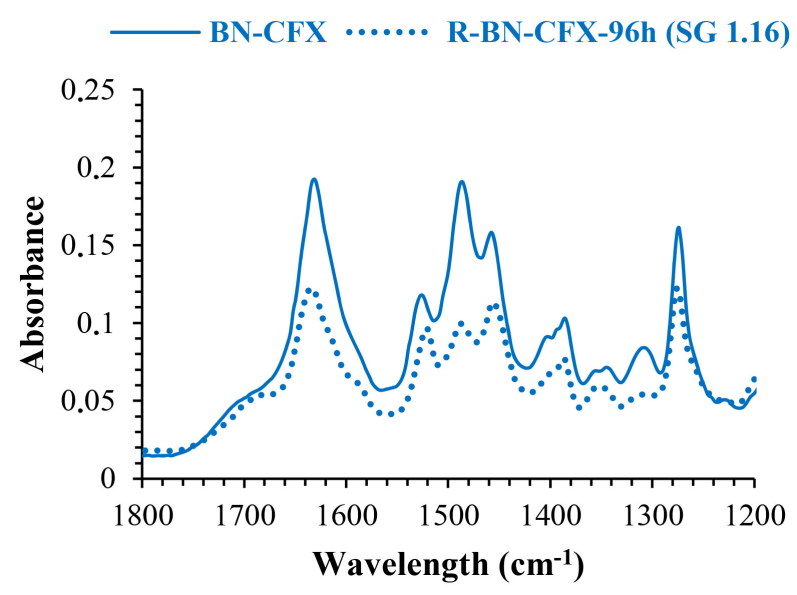

Figure 12. IR spectra of BN-CFX and R-BN-CFX-96h (residue of BN-CFX after $96 \mathrm{~h}$ of release in SG 1.16).

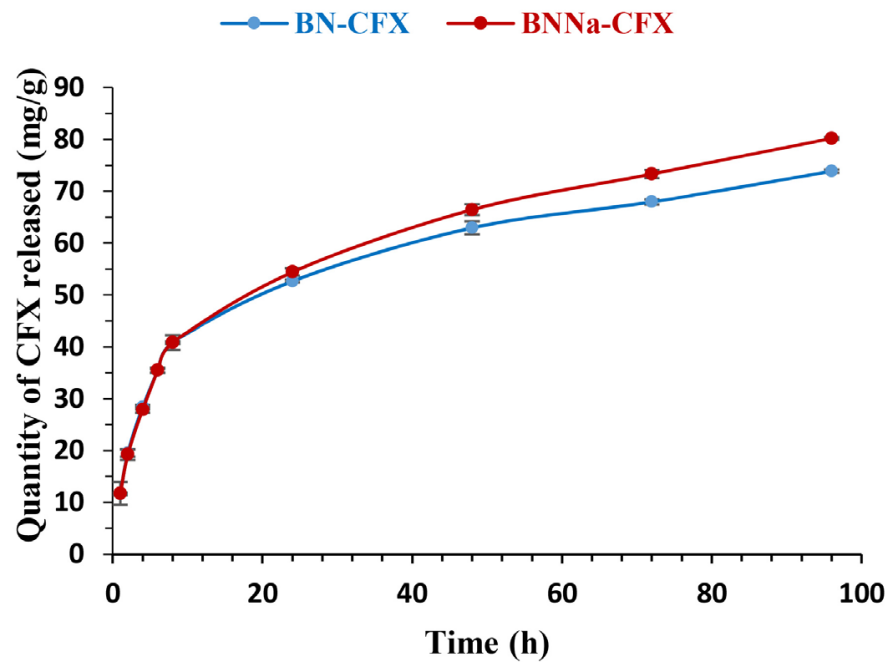

Figure 13. Release profiles of CFX in PBS medium followed by HPLC.

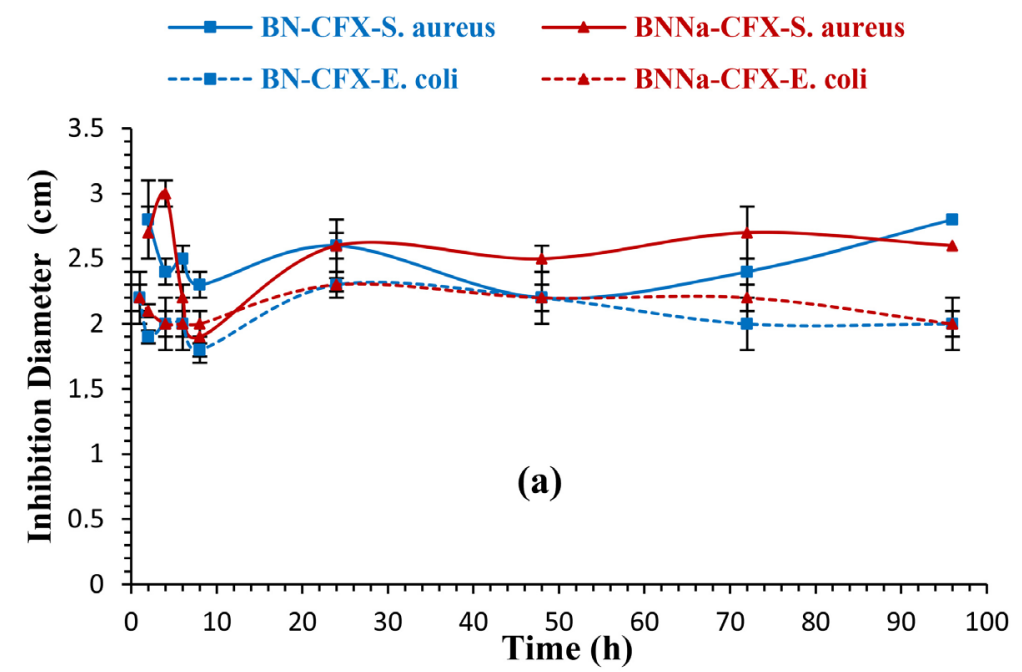

Figure 14. Inhibition diameter of clay-CFX loaded compounds on Escherichia coli and Staphylococcus aureus during 96 h of release in PBS pH 7.4. 


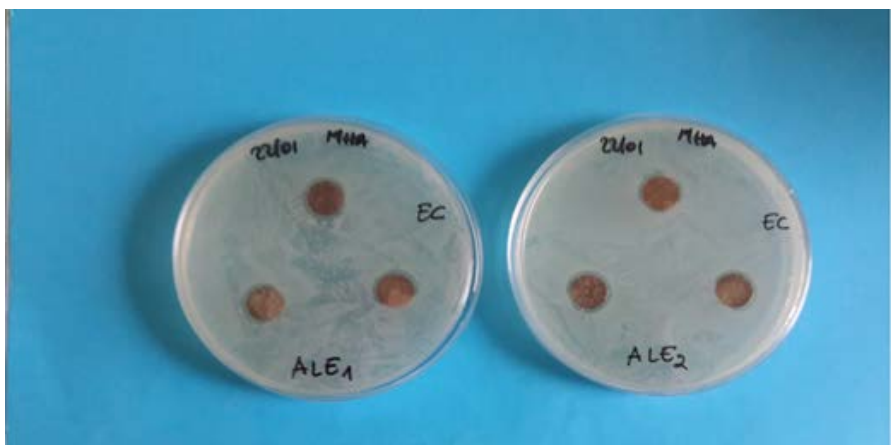

Figure 15. Microbiological assays of raw clays without CFX on Escherichia coli.

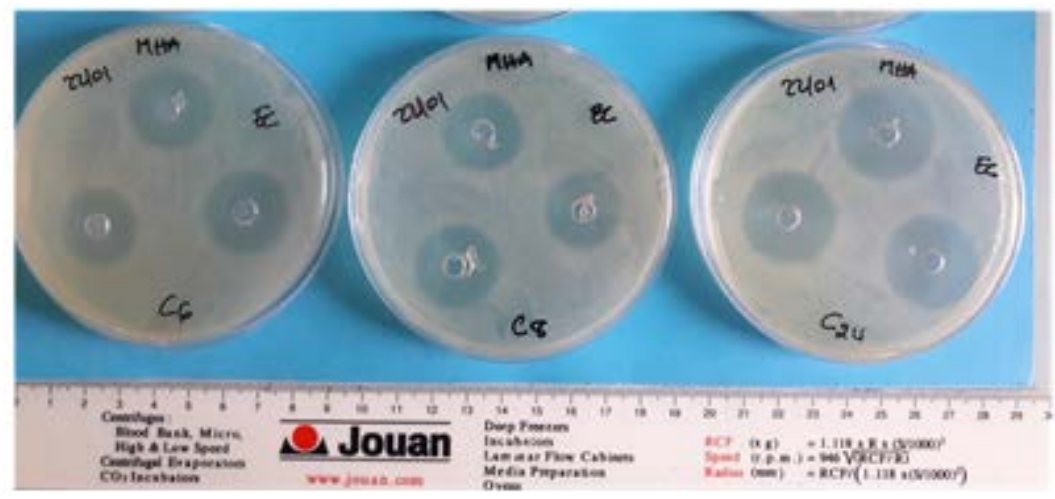

(a)

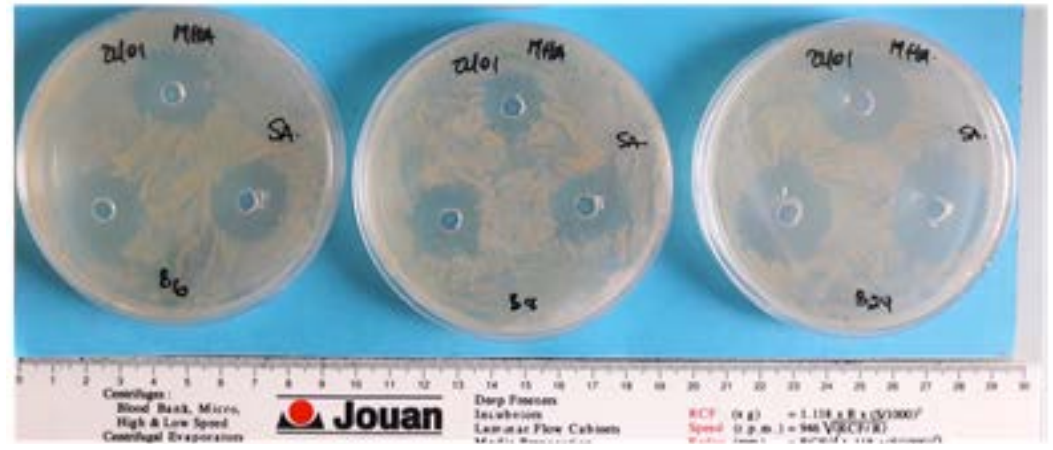

(b)

Figure 16. Bacteriological activities of the release medium withdrawn periodically during 96 hours from CFX-loaded clays suspensions on (a) Escherichia coli and (b) Staphylococcus aureus.

The supernatant solutions in contact with the two CFX loaded clays (Figure 14 and Figure 16) show a microbial activities on $E$. coli and $S$. aureus leading at inhibition radius around $2 \mathrm{~cm}$, while raw clays without CFX do not show any activity (Figure 15): this means that the concentration of CFX liberated in the clays suspensions was above the minimal inhibition concentration (MIC), toward both bacteria strains. As one can see, over the whole study, supernatant solutions in contact with clay-CFX presents more important activity on $S$. aureus than E. co1i. In both cases, inhibition diameter is maintained over $2 \mathrm{~cm}$ and do not drop after 96 hours. This can be explained by the previous release studies (see Figure 
11) that showed that $\sim 70 \%$ of loaded CFX remains loaded after $96 \mathrm{~h}$ hours of liberation, and plays the role of reservoir that constantly delivers CFX in the release medium over the MIC. The antibacterial results could not permit to differentiate performance of $\mathrm{BN}-\mathrm{CFX}$ and $\mathrm{BNNa}-\mathrm{CFX}$ but permit to express bacteriological effects of CFX clay-loaded on bacteria. Inhibition diameter of E. coli and $S$. aureus were sensibly equal regardless to the CFX released concentration.

\section{Conclusions}

This work was dealing with the synthesis of loaded clay-CFX compounds from a smectite coming from Bana, their potential use as drug delivering system of Ciprofloxacin and their antibacterial evaluation on Escherichia coli (E. coli) and Staphylococcus aureus ( $S$. aureus). The smectitic nature of raw clay was obvious from XRD analysis and from some physicochemical properties such as Specific surface areas (SSA).

The raw clay $(\mathrm{BN})$, the homoionic form of the raw clay $(\mathrm{BNNa})$ and the fine fraction of this latter (BNNa-F) have been used for preparation of loaded materials. SSA values for clay samples range as $\mathrm{BN}<\mathrm{BNNa}<\mathrm{BNNa}-\mathrm{F}$, have predicted that CFX intercalation will be in the order $\mathrm{Q}(\mathrm{BN})<\mathrm{Q}(\mathrm{BNNa})<\mathrm{Q}$ (BNNa-F).

The intercalation of CFX within clay matrix was supposed from XRD analysis through the displacement of the basal distance to higher values and has been confirmed by FTIR analysis. Thermal analysis also confirmed CFX presence in the loaded clay-CFX and helped to evaluate the fiability of UV measurements of CFX quantity adsorbed. The intercalation of cationic CFX form in BN, BNNa and BNNa-F occurred very faster with equilibrium reached after $20 \mathrm{~min}$. For optimal CFX concentration, maximum intercalation has been established in the range of 200 to $300 \mathrm{mg} / \mathrm{L}$ for $1 \mathrm{~g}$ of clay with $1 \mathrm{~h}$ of contact time. Although the intercalation is of interest for all clay forms used in this study, homoionic forms induced increased intercalation, in comparison to the raw form, as evidenced from the evaluation of intercalated amount from both thermal and UV-vis analysis.

Enrichment of clay fraction through fine fraction extraction contributes to ameliorate amount of CFX fixed in clay-CFX loaded compounds. The proposed intercalation ratio trend from SSA value has been proven. The release of CFX from the loaded compounds was very fast in time in SG than PBS, but was greater in PBS than SG. Those released in the both dissolution media do not attend $100 \%$ evidence of equilibrium phenomenon of ion exchange during the release by deintercalation process.

The profiles obtained with CFX release indicate a prolonged and continued release in both PBS and SG medium with an initial "burst release" observed in SG. Those profiles have been also obtained by CFX release experiments followed by HPLC. Inhibiting diameter of clay-CFX samples $(\sim 2 \mathrm{~cm})$ indicated the activity of CFX loaded on $E$. coli and $S$. aureus due exclusively to CFX intercalated 
because raw material did not display any effect on those bacteria. The minimal inhibition concentration in the suspension media to inhibit E. coli and $S$. aureus has been reached within $1 \mathrm{~h}$.

From this work, evidence occurs that Bana raw clay used can easily accommodate CFX and clay-CFX compound can be used as ciprofloxacin drug delivery systems. Specific clay loaded compounds can be elaborated and used as bandage in gastrointestinal treatment or as absorbent in some cosmetic formulations.

\section{Acknowledgements}

Feudjio Memenfo is thankful to the French Government for financing her works through the Cultural Cooperation and Action Service (SCAC) scholarship. She is also indebted to Laurence Burylo, research engineer at National Graduate School of Engineering Chemistry of Lille (ENSCL) for X-ray diffractometry analysis and Jean-Noël Staelens, laboratory technician at UMET. The author also thanks Nicolas Blanchemain, Professor at University of Lille for facilitating the access to bacteriological analysis.

\section{Conflicts of Interest}

The authors declare no conflicts of interest regarding the publication of this paper.

\section{References}

[1] Kevadiya, B., Rahul, P., Mahendrapalsingh, M., Shalini, R., Harshad, B., Joshi, G., Ganga, P., Haresh, M., Pankaj, K. and Bajaj, H. (2012) Montmorillonite/Poly-(ع-Caprolactone) Composites as Versatile Layered Material: Reservoirs for Anticancer Drug and Controlled Release Property. European Journal of Pharmaceutical Sciences, 47, 265-272. https://doi.org/10.1016/j.ejps.2012.04.009

[2] Shilpa, J. and Monika, D. (2014) Naturally Occuring Clay, Montmorillonite, as a Drug Delivery Vehicle for in Vitro Extended Release of Venlafaxine Hydrochloride. European Chemical Bulletin, 3, 672-681.

[3] Aghamelu, O. and Okogbue, O. (2015) Characterization of Some Clays from Nigeria for Their Use in Drilling Mud. Applied Clay Science, 116-117, 158-166. https://doi.org/10.1016/j.clay.2015.08.025

[4] Modabberi, S., Namayandeh, A., López-Galindo, A., Viseras, C., Massimo, S. and Mohsen, R. (2015) Characterization of Iranian Bentonites to Be Used as Pharmaceutical Materials. Applied Clay Science, 116-117, 193-201. https://doi.org/10.1016/j.clay.2015.03.013

[5] Hou, D., Hu, S., Huang, Y., Gui, R., Zhang, L., Tao, Q., et al. (2016) Preparation and in Vitro Study of Lipid Nanoparticles Encapsulating Drug Loaded Montmorillonite for Ocular Delivery. Applied Clay Science, 119, 277-283. https://doi.org/10.1016/j.clay.2015.10.028

[6] Isabel Carretero, M. and Pozo, M. (2009) Clay and Non-Clay Minerals in the Pharmaceutical Industry Part I. Excipients and Medical Applications. Applied Clay Science, 46, 73-80. https://doi.org/10.1016/j.clay.2009.07.017

[7] Joshi, G., Kevadiya, B., Patel, A., Bajaj, H. and Jasra, V. (2009) Montmorillonite as a 
Drug Delivery System: Intercalation and in Vitro Release of Timolol Maleate. International Journal of Pharmaceutics, 374, 53-57. https://doi.org/10.1016/j.ijpharm.2009.03.004

[8] Joshi, G., Patel, A., Kevadiya, B. and Bajaj, H. (2009) Montmorillonite Intercalated with Vitamin B 1 as Drug Carrier. Applied Clay Science, 45, 248-253.

https://doi.org/10.1016/j.clay.2009.06.001

[9] Aguzzi, C., Cerezo, P., Viseras, C. and Caramella, C. (2007) Use of Clays as Drug Delivery Systems: Possibilities and Limitations. Applied Clay Science, 36, 22-36. https://doi.org/10.1016/j.clay.2006.06.015

[10] Baek, M., Choy, J.-H. and Choi, S.-J. (2012) Montmorillonite Intercalated with Glutathione for Antioxidant Delivery: Synthesis, Characterization, and Bioavailability Evaluation. International Journal of Pharmaceutics, 425, 29-34.

https://doi.org/10.1016/j.ijpharm.2012.01.015

[11] Wang, C.-J., Li, Z. and Jiang, W.-T. (2011) Adsorption of Ciprofloxacin on 2:1 Dioctahedral Clay Minerals. Applied Clay Science, 53, 723-728.

https://doi.org/10.1016/j.clay.2011.06.014

[12] Wu, Q., Li, Z., Hong, H., Li, R. and Jiang, W.-T. (2013) Desorption of Ciprofloxacin from Clay Mineral Surfaces. Water Research, 47, 259-268.

https://doi.org/10.1016/j.watres.2012.10.010

[13] Chen, H., Gao, B., Yang, L.-Y. and Ma, L.Q. (2015) Montmorillonite Enhanced Ciprofloxacin Transport in Saturated Porous Media with Sorbed Ciprofloxacin Showing Antibiotic Activity. Journal of Contaminant Hydrology, 173, 1-7.

https://doi.org/10.1016/j.jconhyd.2014.11.010

[14] Hamilton, A., Hutcheon, G., Roberts, M. and Gaskell, E. (2014) Formulation and Antibacterial Profiles of Clay-Ciprofloxacin Composites. Applied Clay Science, 87, 129135. https://doi.org/10.1016/j.clay.2013.10.020

[15] Rivera, A., Valdés, L., Jiménez, J., Pérez, I., Lam, A., Altshuler, E., Ménorval, L., Fossum, J., Hansen, E. and Rozynek, Z. (2016) Smectite as Ciprofloxacin Delivery System: Intercalation and Temperature-Controlled Release Properties. Applied Clay Science, 124-125, 150-156. https://doi.org/10.1016/j.clay.2016.02.006

[16] Kevadiya, B., Rajkumar, S., Bajaj, H., Chettiar, S., Gosai, K., Brahmbhatt, H., Bhatt S., Barvaliya, K., et al. (2014) Biodegradable Gelatin-Ciprofloxacin-Montmorillonite Composite Hydrogels for Controlled Drug Release and Wound Dressing Application. Colloids and Surfaces B: Biointerfaces, 122, 175-183.

https://doi.org/10.1016/j.colsurfb.2014.06.051

[17] Rapacz-Kmita, A., Stodolak-Zych, E., Ziabka, M., Rozycka, A. and Dudek, M. (2015) Instrumental Characterization of the Smectite Clay-Gentamicin Hybrids. Bulletin of Materials Science, 38, 1069-1078.

https://doi.org/10.1007/s12034-015-0943-7

[18] Kariminia, S., Shamsipur, A. and Shamsipur, M. (2016) Analytical Characteristics and Application of Novel Chitosan Coated Magnetic Nanoparticles as an Efficient Drug Delivery System for Ciprofloxacin. Enhanced Drug Release Kinetics by Low-Frequency Ultrasounds. Journal of Pharmaceutical and Biomedical Analysis, 129, 450457. https://doi.org/10.1016/j.jpba.2016.07.016

[19] Mache, J. (2013) Minéralogie et propriétés physico-chimiques des smectites de Bana et Sabga (Cameroun). Utilisation dans la décoloration d'une huile végétale alimentaire. Thèse de Doctorat, Université de Liège, Liège, $143 \mathrm{p}$.

[20] Carabineiro, S.A.C., Thavorn-Amornsri, T., Pereira, M.F.R., Serp, P. and Figueiredo, J.L. (2012) Comparison between Activated Carbon, Carbon Xerogel and Carbon 
Nanotubes for the Adsorption of the Antibiotic Ciprofloxacin. Catalysis Today, 186, 29-34. https://doi.org/10.1016/j.cattod.2011.08.020

[21] Carrado, K., Decarreau, A., Petit, S., Bergaya, F. and Lagaly, G. (2006) Synthetic Clay Minerals and Purification of Natural Clays. In: Bergaya, F., Theng, B.K.G. and Lagaly, G., Eds., Handbook of Clay Science, Vol. 1, Elsevier, Amsterdam, 115-139. https://doi.org/10.1016/S1572-4352(05)01004-4

[22] Lagaly, G. (2006) Colloid Clay Sciences. In: Bergaya, F., Theng, B.K.G. and Lagaly, G., Eds., Handbook of Clay Science, Vol. 1, Elsevier, Amsterdam, 141-245.

[23] Thiry, M., Carrillo, N., Franke, C. and Martineau, N. (2013) Technique de préparation des minéraux argileux en vue de l'analyse par diffraction des rayons-X et introduction à l'interprétation des diagrammes.

https://hal-mines-paristech.archives-ouvertes.fr/hal-00872214

[24] Youboue, K., Bongoua-Devisme, A., Kouadio, K. and Yao-Kouame, A. (2014) Minéralogie de la fraction argileuse des sols brunifiés de Kahankro et Anikro (Toumodi) dans le Centre Sud de la Côte d'Ivoire. International Journal of Biological and Chemical Sciences, 8, 1269-1280. https://doi.org/10.4314/ijbcs.v8i3.40

[25] Bergaya, F. and Lagaly, G. (2006) General Introduction: Clays, Clay Minerals and Clay Science. In: Bergaya, F., Theng, B.K.G. and Lagaly, G., Eds., Handbooks of Clay Science, Vol. 1, Elsevier, Amsterdam, 1-18. https://doi.org/10.1016/S1572-4352(05)01001-9

[26] Karym, H., El Mahi, C.M., Benmokhtar, S., Belaaouad, S. and Moutaabbid, M. (2015) Characterization of the Kaolinite Clay Minerals (Nador-North Morocco) Using Infrared Spectroscopy and Calorimetry of Dissolution. International Journal of Recent Scientific Research, 6, 4444-4448.

[27] Hou, D., Gui, R., Hu, S., Huang, Y., Feng, Z. and Ping, Q. (2015) Preparation and Characterization of Novel Drug-Inserted Montmorillonite Chitosan Carriers for Ocular Drug Delivery. Advances in Nanoparticles, 4, 70-84. https://doi.org/10.4236/anp.2015.43009

[28] Wu, Q., Li, Z., Hong, H., Yin, K. and Tie, L. (2010) Adsorption and Intercalation of Ciprofloxacin on Montmorillonite. Applied Clay Science, 50, 204-211.

https://doi.org/10.1016/j.clay.2010.08.001

[29] Stojvovij, A., Tajber, L., Paluch, J., Djuri, Z., Paroj J. and Corrigan I. (2014) Biopharmaceutical Characterization of Ciprofloxacin-Metallic Ion Interactions: Comparative Study into the Effect of Aluminium, Calcium, Zinc and Iron on Drug Solubility and Dissolution. Acta Pharmaceutica, 64, 77-88.

https://doi.org/10.2478/acph-2014-0007

[30] Chang, P.-H., Jiang, W.-T., Li, Z., Kuo, C.-Y., Wu, Q., Jean, J.-S., et al. (2016) Interaction of Ciprofloxacin and Probe Compounds with Palygorskite PFl-1. Journal of Hazardous Materials, 303, 55-63. https://doi.org/10.1016/j.jhazmat.2015.10.012

[31] Jiang, W.-T., Wang, C.-J. and Li, Z. (2012) Intercalation of Ciprofloxacin Accompanied by Dehydration in Rectorite. Applied Clay Science, 74, 74-80. https://doi.org/10.1016/j.clay.2012.07.009

[32] Bentahar, Y. (2017) Caractérisation physico-chimique des argiles marocaines: Application à l'adsorption de l'arsenic et des colorants cationiques en solution aqueuse. Thèse de Doctorat, Université de Nice-Sophia Antipolis, Nice, 170 p.

[33] Lal, S. and Datta, M. (2014) Organoclay Pluronic F68-Montmorillonite, as a Sustainable Release Drug Delivery Vehicule for Propranolol Hydrochloride. European Chemical Bulletin, 3, 593-604. 